\title{
The Critic as Artist: Oscar Wilde's Prolegomena to Shape Grammars
}

\author{
George Stiny ${ }^{1}$
}

\begin{abstract}
Shape grammars include Wilde's aesthetic (critical) method-I can calculate with shapes as in themselves they really are not. Embedding makes this possible with schemas and rules that are "superb in [their] changes and contradictions".
\end{abstract}

Keywords Shape grammars $\cdot$ Embedding $\cdot$ Schemas $\cdot$ Rules

The title of this essay shortens my original one that failed editorial muster-it's the concatenation of Wilde's main title (in italics) and mine. But the expurgated pieces are key-Wilde's subtitles

Part I: With some remarks on the importance of doing nothing

Part II: With some remarks on the importance of discussing everything

and a parallel caption of my own

With some remarks on the importance of calculating without symbols

These rhetorical flourishes are meant to delineate my essay and in fact, take it from where it begins to where it ends, discussing myriad things in between.

There are twin ways to look at the relationship between seeing and calculating, each one described in a different metaphor

George Stiny

stiny@mit.edu

1 Department of Architecture, Massachusetts Institute of Technology, 7-304C, 77 Massachusetts Avenue, Cambridge, MA 02139, USA 
1. Seeing is calculating

and inverting this commonplace today to get

2. Calculating is seeing

Researchers in the brain and cognitive sciences and in computer science are working to solve 1. Dana Ballard provides a generous account of brain computation that includes seeing and strives to explain creative work-Michelangelo and Shakespeare-in terms of brain activity [2015]. But this isn't my goal. My eyes are fixed squarely on 2. I take seeing for granted and go on from there to talk about visual calculating, and what it might mean. I want to explain creative art and design, toonot by studying the brain, but by adding to what calculating does. My problem isn't how seeing works-I know that already, doing it and believing whatever I see. My problem is how calculating works, given that I have the ability to see. This leads straight to shape grammars with schemas for rules, and then to embedding to let rules change what I see freely [Stiny 2006]. This isn't the standard stuff that's taken for granted in brain computation, and it may appear strangely idiosyncratic. Surely, Alan Turing and Alonzo Church defined symbolic calculating comprehensively, and once and for all nearly 80 years ago. Why bother with the question of what calculating is, when it's been decided in mathematics and logic, and confirmed in everyday practice? Everyone knows from experience what computers do-they're indispensible in many ways - but is it possible that there's more to calculating that's waiting to be used? The Turing-Church thesis is only that, a good guess, not a solid proof that all calculating is combinatory with invariant units (primitives). What if calculating is like painting, where what I see changes as I look at things in an openended process with indefinite goals, or at least goals that alter without rhyme or reason? What if surprises (unexpected shifts in what I see) aren't something to fix but the reason for going on? No-whatever calculating is, it isn't that; calculating isn't about surprises and making use of them in surprising ways. How can I take something that's unexpected, that I haven't seen before, and that I may not understand, and use it? Surprises are confusing and usually mess up my plans. It's wild - even dangerous — to think that calculating is seeing. In calculating, things are clear and distinct. Symbols are strictly what they are in themselves-alone or in combination, 0's and 1's are 0's and 1's that are always the same all-or-none bits (units) with nothing in between. There's simply no room for anything to be vague or ambiguous, or different than it is.

But maybe painting isn't such a bad idea. Herbert Simon, a giant in computers and cognitive science, suggests as much when he describes design as painting in his still seminal The Sciences of the Artificial, but later in a second edition, in a new chapter on social planning. It appears that Simon didn't finish the first time around-there was more to say of real importance about design

Making complex designs that are implemented over a long period of time and continually modified in the course of implementation has much in common with painting in oil. In oil painting every new spot of pigment laid on the canvas creates some kind of pattern that provides a continuing source of new ideas to the painter. The painting process is a process of cyclical interaction 
between painter and canvas in which current goals lead to new applications of paint, while the gradually changing pattern suggests new goals [1981: 187].

But don't be misled. Simon takes a strikingly Epicurean approach to painting that denies what I see, and the everyday physics of paint

I shall emphasize ... that forms can proliferate in this way because the more complex arise out of a combinatoric play upon the simpler. The larger and richer the collection of building blocks that is available for construction, the more elaborate are the structures that can be generated [1981: 189].

Lucretius's epic poem On the Nature of Things limns the Epicurean swerve needed for atoms to collide freely and link, to create what's in the world. (Today, atoms attach in many ways, some even for self-assembly. In synthetic biology, BioBricks have sticky ends, while Legos line up pins and holes, and Velcro puts hooks in loops). Epicurus's colliding atoms and Simon's combinatoric play with building blocks are close in spirit, if not exactly the same. Both start out with units that are independent in combination - a good way to calculate-but where Simon assembles building blocks in different ways to satisfy a given test (fixed description), the atomic swerve is capricious to let in free will. Of course, Epicurus doesn't stop with his enduring invention; he ties thinking to seeing, as well-they're not atoms-and encourages plural causes, else we "fall away from the study of nature altogether and tumble into myth [choose a single point of view, even as multiple perspectives are equally true]" [Diogenes Laertius 1950: 617]. This is the opposite of Ockham's razor that's indispensible in science and logic, but it's just right for painting, and for art and design. Seeing and plurality are key in shape grammars. My point of view isn't fixed, but alters every time I try a rule, and any perspective I take now is as true as any one I've taken before-even if there's a contradiction. It isn't necessary that I begin with a collection (vocabulary) of building blocks to calculate-they change with everything else as I go on. Well, maybe-but Simon's combinatoric play with building blocks is, undoubtedly, the logical way to calculate. Turing and Church would unswervingly approve. And no one doubts that it's the most parsimonious way, as well-in fact, for most, there aren't any options. But for me, there are alternatives in shape grammars. As the way to paint, combinatoric play with building blocks is an awkward start; as the only way to calculate, it tumbles into myth. Building blocks (units) and tests aren't enough for art and design; they aren't necessary to calculate.

Nonetheless, I'm pretty sure Simon is onto something big when he puts design in painting, and precisely for the reason he gives-things change as I go on independent of my original intentions and goals, if I know (remember) what they are, or I pretend to. (Elliot Eisner touts "flexible purposing" in art education for this reason, too [2002]). There are always surprises and plenty of room for new insights-I'm free to change my mind to see as I wish. Insight—seeing things in new ways-is, surely, what creative activity is about, and shape grammars show how this is calculating. They make it easy, because rules apply with no inherent memory. Every time I look at anything, it's for the first time-right now, with nothing definite beforehand or ahead. I'm free to see four triangles 


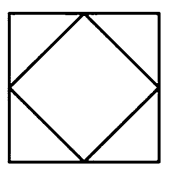

even if I tell you I've drawn two squares and that I intended to. What I mean is entirely clear, and so is what I see. Experienced draftsmen (computers have replaced most of them) used to draw like this, with longest lines (maximal elements), and then see what they pleased, embedding this to make that. Ivan Sutherland considers this an entirely unruly process with dirty marks on paper [1975: 75]. His pioneering programs for computer-aided design, parametric models, and computer graphics are disciplined and prophylactic-because they have an underlying structure, as Simon notes admiringly [1981: 154]_but they also have a blind spot for triangles. And there are pentagons, hexagons, and big K's and little k's in vast excess. Simon and Sutherland are willing to give up a lot to calculate. But no one seems to be concerned-or conceals it if they are. Now more than ever, computers are too powerful to fret about trivial limitations - they vanish in the blinding dazzle of digital-success. There's scant reason to see when you can count really fast. Speed and data overwhelm mere insight.

Not everyone is willing to forego the accidental (illicit) pleasures of seeing freely - and the creative opportunity this affords - for the certainty and predictability of invariant and consistent structure that computers rely on to draw, etc. In his famous essay, The Critic as Artist, Oscar Wilde elaborates a purely aesthetic method that's "superb in [its] changes and contradictions" [1982: 391]. Wilde inverts Mathew Arnold's apodictic critical formula to suit himself, so that "the primary aim of the critic is to see the object as in itself it really is not" [1982: 369]. (I suppose this is what I'm trying to do for calculating). Wilde's aesthetic method isn't objective, certainty is never the goal-neither axiomatic in logic nor Bayesian in big data. This evidently isn't for Wilde, especially not the latter- "No ignoble considerations of probability, that cowardly concession to the tedious repetitions of domestic and public life, affect it ever" [1982: 365]. And Wilde isn't alone; he aligns with diverse artists-painters, poets, philosophers, and essayists—in crucial ways. One axis running through art and design is defined with Leon Battista Alberti. In the opening lines of De Statua, Alberti diligently observes landscapes rife with contours and outlines at the source of creative work [1972: 121]. He takes what he sees in random things - "a tree-trunk or clod of earth"-and refines and corrects lines and surfaces in many ways to form images and likenesses of real things. (This switches easily to begin with actual faces and other real things-even pictures. I guess all seeing works like this). William Shakespeare does the same in the wild wood, where he indulges fancy with no bounds; he admits plural causes and supposes a bush a bear, in branches and leaves, or in the empty spaces in between

Such tricks hath strong imagination,

That if it would but apprehend some joy,

It comprehends some bringer of that joy;

Or in the night, imagining some fear, 
How easy is a bush supposed a bear! [2009: 143, 145]

Even as wild fancy, this is a creative insight that I can act on as I please, seeing exactly as Alberti suggests. But unrestrained, strong imagination is likely to be disorienting. It takes what John Keats aptly names "negative capability"-holding on to "uncertainties, Mysteries, doubts, without any irritable reaching after fact and reason" [1958: 193]. To embrace all that ambiguity allows, and not try to limit this with insipid proofs and lifeless certainty, is the heart of the matter. All descriptions are true and none is final. For Wilde, beauty is the only goal, and this varies freely in his artist/critic, who knows that

Beauty ... whispers of a thousand different things which were not present in the mind of him who carved the statue or painted the panel or graved the gem [1982: 369].

and takes these undertones anywhere they lead

You see then how the aesthetic critic [as artist] ... seeks rather for such modes as suggest reverie and mood, and by their imaginative beauty make all interpretations true and no interpretation final [1982: 370].

Modes for reverie and mood may seem a tall order, but really, they only change what I see-at will, in the free flow of creative experience. This is the full importance of doing nothing, of taking all the time in the world for observation and contemplation, carried by caprice wherever it goes. It's the imaginative root of Wilde's aesthetic method and of Alberti's landscapes and contours, as well. The idea is secure in Wilde's critical spirit, before things are divided and namedPlato's artists wander lost in a maze, and as Wilde drifts with every passion, William James is caught in a stream of consciousness, and Walter Pater is in a whirlpool of impulse and privileged moments (epiphanies). But more, it's how embedding works to make calculating an open-ended process that can go in any direction. The schemas in a shape grammar and the myriad rules that they define in unrestricted assignments- "modes as suggest reverie and mood"-let me wander as widely as I please, to see whatever I wish. Shapes express entirely what's impressed on them, that's embedded with rules I choose for myself

The longer I study, Ernest, the more clearly I see that the beauty of the visible arts is, as the beauty of music, impressive primarily, and that it may be marred, and indeed often is so, by any excess of intellectual intention on the part of the artist. For when the work is finished it has, as it were, an independent life of its own, and may deliver a message far other than that which was put into its lips to say [1982: 368].

Every time I try another rule to see things in ever-new ways, there's insight, and with it, delight. This is, no doubt, disturbing. Everyone knows the artist/critic doesn't calculate. At the very least, this seems scant of refinement and sensitivity, and to flaunt "an excess of intellectual intention". But reverie and mood won't be denied. Dreams go least where anyone expects. Maybe calculating is more like an 
American cowboy (a drifter) painting the town red. The slang is all American, and as Wilde appreciates, only Americans have Walt Whitman, and borrow their slang from the highest literature (The Devine Comedy of Dante) [Healy 1904: 134-135]. This seems reason enough for my dreams to begin with painting - to turn high art into crude calculating (inverting things is Wilde's aesthetic method), and far more to keep seeing forever changing, in the here and now, neither past nor future, at the quick of experience. (In The Poetry of the Present, D. H. Lawrence applies this to Whitman's "unrestful, ungraspable poetry of the sheer present, poetry whose very permanency lies in its wind-like transit" [1993: 183]). Shape grammars overlap the artist/critic in untold ways.

My use of Wilde here and throughout this essay accomplishes two things. First, Wilde is a provocative way to introduce some central themes in shape grammars. The members of my graduate seminar-old and new-found him exhilarating and usefully thought-provoking, as a locus for discussion, especially with shape grammars and how they handle his concerns. Wilde lays out an aesthetic taxonomy that ties up to many of the key ideas in visual calculating. Moreover, I can show that shape grammars include Wilde-what better evidence is there that they're exactly right for art in its purest, most demanding modes and forms (Wilde's words)? In fact, shape grammars often suggest more than Wilde's critical method, with greater focus and force. I suppose it's because they're a way to calculate. But there are others who add to this-who confront what it means to calculate with their eyes.

The Gestalt psychologist Wolfgang Köhler reviewed Norbert Wiener's classic Cybernetics soon after it appeared. Kohler noticed that machines and calculating lack insight [1951]. Warren McCulloch and Walter Pitts, Wiener's fellow cyberneticists, had already shown that neural nets calculate whatever I can describe in words. Even so, McCulloch agreed with Köhler-I suppose because words aren't enough. "The problem of insight, or intuition, or invention-call it what you willwe do not understand" [McCulloch 1965: 14]. Descriptions are incomplete and are never enough - but what happens before insight, if it isn't a result of calculating? This overwhelms cybernetics, and computers and Simon's sciences of the artificial alike, including AI. "Insight remains handmade" [Gondek 2014]. But shape grammars take a stunningly different tack, where seeing is all that I need and describing things before I calculate isn't necessary. That's what embedding is for, to see. Descriptions are the result of calculating and aren't a prerequisite. Descriptions vary as I calculate; they're empty before I start and incomplete as long as I go onwith no end in sight. Shape grammars are a kind of insight engine. This is an ambitious goal for visual calculating, but whether it's symbolic calculating or not is something to consider first.

The reverse of this is easy to show-symbolic calculating with Turing machines (computers) is a special case of visual calculating with shape grammars [Stiny 2006: 272-273]. Intuitively, the result seems pretty obvious, if not immediate. Turing machines and shape grammars both involve recursion, but Turing machines depend on an identity relation for symbols that's the same as embedding for 0-dimensional elements like points. If one point is embedded in another, they're identical. Embedding for higher-dimensional elements-lines, planes, and solids-doesn't work this way; it's a partial order. One element can be embedded in another without 
identity. However, whether Turing machines include shape grammars no matter what remains, to some extent, an open question. There's equality, although it takes a real effort to show, for elements with linear descriptions-points, lines, planes, and solids-and conics, and, no doubt, more up the polynomial ladder [Stiny 2006: 275-277]. A pretty credible result; even so, is it strong enough for everything I can see? Brain computation implies this if it's a Turing machine-I use my brain to see. But until this is a proven fact, I'll fret. Are there things I can see that I can't represent (describe) or simulate in Turing machines with polynomials and added math and logic? And even with equality, are Turing machines a good way to talk about shape grammars? Turning a visual process into a symbolic one is a scientific triumph, but empty, if there isn't room to see. I'd rather stick to shape grammars, and agree to make them Turing machines if asked. My visual intuitions are too vital to abandon. Trying computers to calculate with shapes in easy ways shows why shape grammars are worth keeping.

For computers (Turing machines), what I'm able to do typically depends on the descriptions I use to calculate. This is so in AI-at Stanford, John McCarthy takes it as an article of faith and a personal source of pride [2009] — and it's a common practice in object-oriented programming. I can make up my mind (forget how I do this) that there are two squares in the shape

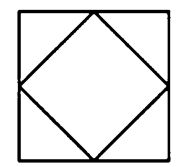

and that each is a symbol as in a Turing machine or equivalently, an object with definite properties, maybe position, size, etc. If I use this to describe the shape as a set of two squares, one a transformation t of the other, or more exactly, as a spatial relation

\section{$\{$ Square, $\mathrm{t}($ Square $)\}$}

it's hard to see or imagine other polygons or letters-triangles, pentagons, hexagons, K's and k's. And if I add this up, it's indefinitely many things that I may miss-so much for insight and many of my intuitions. I have no trouble seeing this or tracing it out-my hands and eyes are the same-but I can't do it with two squares. Maybe I can change my description, but how do I decide how to do that before I've seen what's there? Does this prove that calculating isn't seeing? Well, maybe for symbolic calculating with Turing machines - at least it doesn't look simple-but what about visual calculating with shape grammars. There's abundant opportunity to describe things there, too, but as the result of calculating and not before I start. That's a huge difference, and it's why Wilde has so much to say about visual calculating. I can drift with the rules I use to see- "modes as suggest reverie and mood". Anytime I look, no matter where, it's going to be new, and there's always the chance for more. It's surprising how little it takes for this to happen. Identity rules in the schema 


$$
\mathrm{x} \rightarrow \mathrm{x}
$$

more than suffice-showing the importance of doing nothing, merely seeing to calculate. The contents of a line exceed whatever time I take to try identities. That a line is a line is all I need

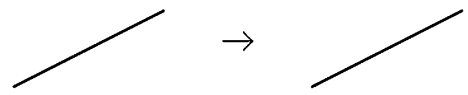

(If I add copies of this identity, I can pick out any part of any shape). I can go on as long as I please. Alberti appreciates this, and with greater power, so does William Blake

For a Line or Lineament is not formed by Chance: a Line is a Line in its Minutest Subdivisions: Strait or Crooked It is Itself \& Not Intermeasurable with or by any Thing Else [1974: 878].

Blake is famous for his granular view of infinity that's something of an adolescent cliché. But the line, a simple segment

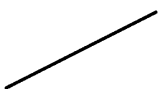

is sublime. It invariably overwhelms the artist and critic alike. It would impress Edmund Burke with its sheer vastness, although William Hogarth can see only stasis and death in unyielding uniformity, preferring instead the serpentine that parametrically inflects the line

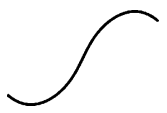

as a locus of beauty. But "Strait or Crooked," a line is a line with endless patterns and devices embedded in it, that's intricate in all of its changes and contradictions. Wilde's critic is, truly, an artist, and shape grammars show why.

It's not simply how descriptions work in shape grammars, it's also what's to be described, and where and when. There's a stubborn ambiguity in the things (shapes) I see-being one way or another seems never enough. The descriptions (names) I use don't stick. They're incomplete-whenever I look, there's more to see that needs to be added in. (It's easy to leave who and why outside of visual calculating and the details of shape grammars. I typically assume I'm who, and why is because it's fun. This strikes me as a perfectly natural assumption in sync with shape grammars, and what they do. Seeing is an inherently personal way to calculate, and the ability to see in diverse ways, to be surprised, "eureka, I've found it," is a marvelous delight. Where would painting be, and art and design, without delight? See Wilde [1982: 365]). 
How descriptions work depends first on schemas and assignments to define rules, and then on embedding and transformations (usually linear ones, but this isn't a requirement) to apply rules. I'm free to apply a rule $\mathrm{A} \rightarrow \mathrm{B}$ to a shape $\mathrm{C}$ when there's a transformation that embeds the shape $\mathrm{A}$ - what - in $\mathrm{C}$, and so determines where. The goal is to find a part of $C$ that's like A, and the shape $t(A)$ may be any part of $\mathrm{C}$, including all of $\mathrm{C}$ itself. This isn't the standard way to calculate in computers (Turing machines) with minimal units (symbols) that match identically, and precise addresses. Whatever parts $C$ has (units or not), they aren't specified in advance-without A, there aren't any parts to find. Moreover, parts are dispersed and may interact in strange ways. In the shape

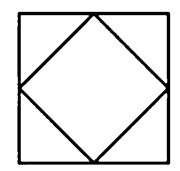

there are four pentagons like this one

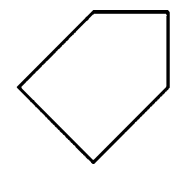

but if I erase any one of these pentagons, the other three disappear. And there's even more magic in letters. How many K's and k's vanish if I erase any one of either? The rule $\mathrm{A} \rightarrow \mathrm{B}$ describes $\mathrm{C}$ with respect to $\mathrm{t}(\mathrm{A})$ and the rest of $\mathrm{C}$, that is to say, its relative complement $\mathrm{C}-\mathrm{t}(\mathrm{A})$. (This also leads to topologies for shapes [Stiny, 2006: 282-287] and if I squint, to trees that show how sentences are divided into phrases and words in a generative grammar. Identity rules work recursively for the latter-if I apply the rule NP $\rightarrow$ NP to a sentence S, where NP is a noun phrase, then $\mathrm{S}-\mathrm{NP}$ is a verb phrase. And there are identities for NP and for $\mathrm{S}-$ $\mathrm{NP}$, etc.). Before I try A $\rightarrow \mathrm{B}, \mathrm{C}$ doesn't have parts-or underlying structure of any kind. I don't know what to say about it or what to do with it until I see $t(A)$. Then, I

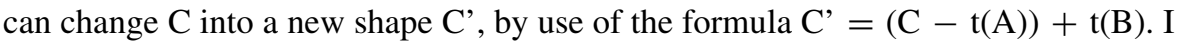
erase $t(A)$ and add the shape $t(B)$ to the result. But what about $C^{\prime}$ - what can I say about it? Well, whatever I want to. The parts that make C' fuse-they aren't preserved when I evaluate $(\mathrm{C}-\mathrm{t}(\mathrm{A}))+\mathrm{t}(\mathrm{B})$, so that embedding isn't limited. I can write out what I did to $\mathrm{C}$ to get $\mathrm{C}^{\prime}$, but there's no memory of this in $\mathrm{C}^{\prime}$ itself-it has no divisions. In fact, $t(B)$ needn't be in $C^{\prime}$ the next time I apply a rule, even though $t(B)$ is what $I$ added to $C-t(A)$. The parts I combine do so seamlessly without even a trace. I need to describe C' whenever I look at it, and that's exactly the reason for rules - to do what I see now. In shape grammars, it's never once and for all, but one more time, with no final goal ever in sight. When is over and over again-I just go on. So, does calculating end? No, it merely pauses between the rules I try. There's always something different to see, and more to describe. That's how it goes-and for painting, and art and design. It's why I hang pictures on my walls and am never tired of looking at them-doing nothing in observation and contemplation is one 
way, maybe the only way, to make art. (Also for pictures, etc. in art museumsthere's art in museums if there's someone to look, and only for those who see. Experts, Aunt Sophie and Uncle Al, critics, curators, docents, historians, etc., make a difference, but this is no substitute for personal experience. Seeing is never secondhand).

Wilde is magnificently aware of this, at least for the critic as artist-who is "both creative and independent" [1982: 364]. The critic deals "with art not as expressive but as impressive purely" [1982: 366]. Shape grammars show that this holds, too, for the artist and designer when they look at their work-finished or ongoing-and choose what rule to try next. For artist and critic alike, there's always more. They're on equal footing, as they go freely this way and that, seeing and doing-first artist as critic, then critic as artist, and intricately entangled. It makes no sense beyond professional decorum to keep the distinction, especially when I calculate with shapes and rules. (The equivalence of artist and critic is also patent in a different way in Algorithmic Aesthetics that I wrote with James Gips [1978]. Still, it's easier to justify with shape grammars, where seeing informs Wilde's aesthetic method of reverie and mood. Many things come rapidly to mind when embedding isn't strictly an identity relation between symbols or units. In reverie, seemingly intractable difficulties vanish-in object-oriented programming, for example, recognizing a rectangle in an addition of two squares with a common side [Smith 1996: 47-49]. Ludwig Wittgenstein considers similar things in the Tractatus when he explains a Necker cube as a complex of constituents related in two different ways [1977: 54]. Pretty neat, although I can do the same without constituents using the identity rule for squares-or an identity for parallelograms. But where do constituents come from? Maybe Wittgenstein's constituents aren't what I imagine them to be-it's unlikely I'll get all I can see, enumerating the combinatorial variants for 0 -dimensional elements (primitives) related in one way or another. Maybe Wittgenstein implies as much

This is connected with the fact that no part of our experience is at the same time a priori.

Whatever we see could be other than it is.

Whatever we can describe at all could be other than it is.

There is no a priori order of things [1977: 58].

And this seems right when Wittgenstein goes on to 1-dimensional figures and more in Remarks on the Foundations of Mathematics. He adds polygons with a common side - a triangle and a hexagon - to get an ambiguous result, and wonders what mathematics, or for that matter, computer programming, would be like if this is how things work [1967: 189e]. Are there two polygons that I can't ignore, or is there more that I'm free to see? Nothing is what it's meant to be. Wittgenstein's a prioripure intention, whether God's or Plato's philosopher's-mars beauty and also calculating. This is embedding and Wilde all at once. Shape grammars are a nice way to see and dream, with no excess intellectual baggage).

A rule $\mathrm{A} \rightarrow \mathrm{B}$ in a shape grammar is easy to represent in a heuristic that helps explain how the rule works. I do what I see, in this way 


\section{see $\mathrm{A} \rightarrow$ do $\mathrm{B}$}

Whether it's the artist or critic who uses the rule (or you or me) is of no consequence-it's exactly the same. When artists look at what they're doing to go on, they're doing what the critic does. And whenever anyone looks closely at anything, they're acting in this way, too. Beautiful things for artist and critic alike are never done-there's always more to see and do. It's important to see as you please, and to discuss everything you find-even with changes and contradictions. There's never a final conclusion. Wilde's critic as artist beholds beautiful things from an individual point of view. Wilde's critical method is himself

The critic occupies the same relation to the work of art that he criticises as the artist does to the visible world of form and colour, or the unseen world of passion and of thought [1982: 364].

It treats the work of art simply as a starting-point for a new creation. It does not confine itself-let us at least suppose for the moment-to discovering the real intention of the artist and accepting that as final. And in this it is right, for the meaning of any beautiful created thing is, at least, as much in the soul of him who looks at it, as it was in his soul who wrought it. Nay, it is rather the beholder who lends to the beautiful thing its myriad meanings, and makes it marvelous for us [1982: 367].

The artist and critic alike are observers, and always for themselves. They see, and what impresses them is in their souls-in the rules they try. Each lends beautiful things their myriad meanings, and is free to take any of these back to see others. The process goes on-how could this be otherwise? Beautiful things, even as they are being made, don't stand up and say, "This is what I'm supposed to be; this is what I'm supposed to mean". And even if they could, how am I supposed to understand that? Do their utterances tell me? It doesn't matter whether beautiful things are rendered visually or verbally - it's simply more of the same. They're incompleteat least they're never complete for the artist or critic individually, or as one. There's everything to add that only rules provide. Seeing and doing are related in rules, and in whatever way I handle the beautiful things around me. And it's what I see that makes the difference. My heuristic holds true-I do what I see. Then, each one of us, individually, is creative and independent.

Describing shapes only starts with the various rules I try. Descriptions of shapes interact, so that the description I use now changes the descriptions I've used before. No description is immune from revision. This is one way to ensure that there's some kind of continuity or consistency as I calculate-in retrospect anyway-no matter how radically the rules I use change what I see [Stiny 2006: 296-301]. There's a lot of room for surprises and no reason to keep what I've done. For as long as I go on, I'm free to revise whatever I've said about the past in whatever way I want, reconfiguring it according to the rules I try now. History works in reverse. The lessons of the past are made in the present; the latter molds the former. As Wilde notes wryly — "The one duty we owe to history is to rewrite it" [1982: 359]. And 
rewriting history is exactly what happens when I calculate in shape grammars. For example, consider the shape

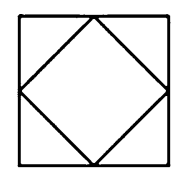

once more, that's two squares or four triangles. And actually, there's no reason to look at anything else. I can always see in another way to make the point I want to make now. There's a tree, that is to say, a description, for each way of seeing the shape, and more when I put these trees together to show how I can see triangles after I've seen squares - and vise versa (sometimes history is reversible). Two squares aren't four triangles - the categories are different and the arithmetic is totally wrong. Squares don't make triangles unless squares and triangles as in themselves (maybe the definitions I learned in school) they really are not. I can use the trees I've already got, either with squares or triangles, to decide what. Describing shapes isn't just once and for all, but open-ended-and for this, there are rules. I'm free to revise what I say in terms of the rules I use to see. I can rewrite history as I please.

John von Neumann, whose name is synonymous with computer architecture and design, worries about describing shapes, too, as visual analogies

Suppose you want to describe the fact that when you look at a triangle you realize that it's a triangle, and you realize this whether it's small or large. It's relatively simple to describe geometrically what is meant: a triangle is a group of three lines arranged in a certain manner. Well, that's fine, except you also recognize as a triangle something whose sides are curved, and a situation where only the vertices are indicated, and something where the interior is shaded and the exterior is not. You can recognize as a triangle many different things, all of which have some indication of a triangle in them, but the more details you try to put in a description of it the longer the description becomes.

In addition, the ability to recognize triangles is just an infinitesimal fraction of the analogies you can visually recognize in geometry, which in turn is an infinitesimal fraction of all the visual analogies you can recognize, each of which you can still describe. But with respect to the whole visual machinery of interpreting a picture, of putting something into a picture, we get into domains which you certainly cannot describe in those terms. Everybody will put an interpretation into a Rorschach test, but the interpretation he puts into it is a function of his whole personality and his whole previous history, and this is supposed to be a very good method of making inferences as to what kind of a person he is [1966: 46-47].

Embedding lets me see triangles without having to say what they are in advancethere's no visual analogy (spatial relation, or alternative description or test) before I calculate. Of course, triangles may be three lines, as von Neumann suggests in his 
visual analogy. And in fact, it's easy to apply the boundary schema $x \rightarrow b(x)$ and its inverse $\mathrm{b}(\mathrm{x}) \rightarrow \mathrm{x}$ (alternatively, $\mathrm{x} \rightarrow \mathrm{b}^{-1}(\mathrm{x})$ ) to switch points and lines and planes, to traverse this graph

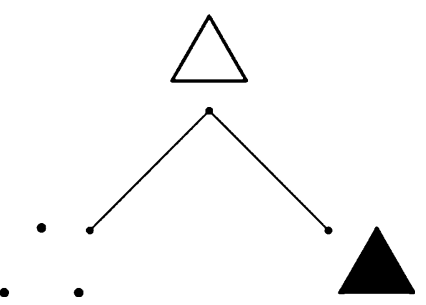

and test for triangles. And if I add a rule, so a line is a serpentine, and its inverse
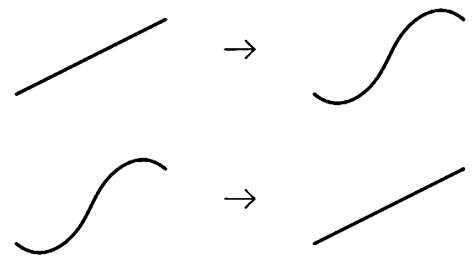

I can complicate the graph in this way

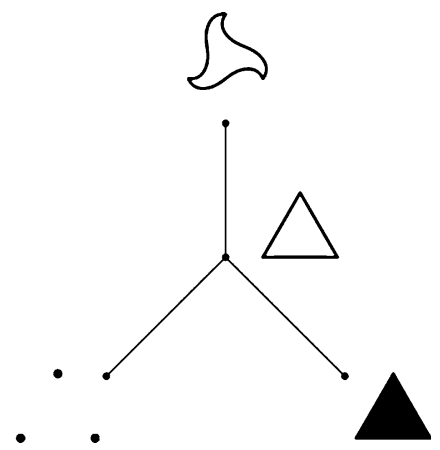

to extend my test. But my rule also gives me more

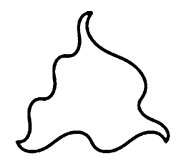

Is this the end of it for triangles? Von Neumann is open to this, but pictures are a hedge; shape grammars show otherwise. Triangles may also be three angles 


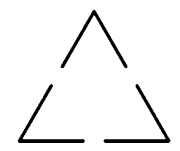

or something entirely different, say, puzzle tiles in "ice-rays" (decorative Chinese lattice designs that evoke cracking ice on a frozen lake)

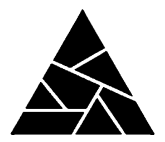

It all depends on the rules I try; seeing doesn't end. But learning visual analogies and using them in place of what I see somehow misses the point. Seeing isn't recitation-they're separate and needn't match. I can recite what I've learned entirely by rote, with my eyes shut tight, blind to everything. Wilde is right to worry about this - "Education is an admirable thing, but it is well to remember from time to time that nothing that is worth knowing can be taught" [1982: 349]. Facts fixed in advance aren't enough, as I calculate to go on-seeing exceeds all of the standard descriptions I memorized in school. Yes, a triangle is three lines and a square is four, and no, this doesn't work all the time. Visual analogies may be horribly incomplete-unless there are teachers and tests (computers) to ensure that everything is correct and no one flouts the law. But I can put anything into a picture. At first, every shape is a Rorschach test, and then, any visual analogy I please. (Surely, a Rorschach test is what a test as in itself it really is not. I can contradict myself freely). Is this von Neumann or Wilde?- "The one characteristic of a beautiful form is that one can put into it whatever one wishes, and see in it whatever one chooses to see" [Wilde 1982: 369]. With embedding, the visual analogies I can see are endless. They're defined on the fly as I go on, and they vary freely with every rule I try. This may be inconsistent and possibly disingenuous. Maybe that's the reason Sutherland spurns dirty marks on paper-the draftsman's drawings are dishonest. But no doubt, this is why Wilde would insist on them"What people call insincerity is simply a method by which we can multiply our personalities" [1982: 393]. I guess that's what the Rorschach test is for, to expose insincerity, as it traces personalities in flux. (At university, it's choosing a major, and later a profession - there's security and comfort in names). I can't describe this in advance of what I see-von Neumann and Wilde would surely agree. This is an extraordinary place for art and science to meet. Von Neumann fears that visual analogies may be incomplete, as Wilde resolves this in his aesthetic method-not once and for all, the possibility von Neumann broaches, or in the invariants so prized in science (try Ockham's razor on a triangle and not miss something), but again and again in an ongoing process. It's like this for visual calculating with shape grammars. (A neat technical result is hard to ignore. Notice that reduction rulesthey're defined by embedding-let me decide if different arrangements of elements, in particular, lines and planes, etc., describe the same shape or not, maybe a triangle [Stiny 2006: 187]. But what the reduction rules don't do is tell me the arrangement 
of elements that makes sense to me now. That depends on how I calculate in a shape grammar with endless opportunities for surprise and change).

Today, the STEM subjects-science, technology, engineering, and math-seem to have eclipsed art and design, even if visual calculating with shape grammars proves just the opposite. It helps to wander around-what's eclipsed and how complete this is, depend on where you stand. Nonetheless, there's MIT engineering and problem solving with mind and hand, that sets clear aims and goals, and takes the MIT path to solutions in STEM. An essential goal is to make the art of innovation a science, presumably with predicable results. But once again, Wilde assumes a critical view that's pretty much like calculating in shape grammars- "It is because Humanity has never known where it was going that it has been able to find its way" [1982: 359]. Simon implies the same in The Sciences of the Artificial-surely, innovation is part of this venture-when he puts design in painting; it's inevitable when I use shape grammars to calculate. There's slight reason to eschew art and design as painting in education, or for artists and designers to adopt engineering methods and give up their studios for research labs, business models, startups, etc. The engineering method at MIT and the aesthetic method of artists and designers are alike when it comes to calculating - in fact, the former may be a special case of the latter, if calculating is merely combinatoric play with building blocks. STEM misjudges its size; it's too small for art and design. I suppose that's why art isn't taught. The successes of mind and hand are obscure without eyes to see. What good is science without art-with both on the same footing, neither in thrall of the other, each with its individual methods? Separately, art and science tumble into myth. It's high time to take art seriously, as a way to describe things as in themselves they really are not. That's the way insight and creativity work, and true innovation, too. There's plenty to gain and nothing to lose if art is art-surely, there's no loss of mathematical or logical rigor, as shape grammars show. I thought that honest standards were the reason for STEM. To keep art out of schools to concentrate on STEM, and to discourage art for the STEM occupations that big business shortsightedly demands constrict education and experience for everyone. Wilde is much too optimistic without art (no doubt, this is something beyond his ken), and all that art lets in, including innovation. Has Humanity lost its way?

The idea that shape grammars don't calculate the same way computers do, with minimal units and addresses, repays another look. Noam Chomsky suggests that units and addresses are the correct way to explain language [2014] - I'm pretty sure Ballard would agree for brain computation generally. Chomsky emphasizes recursion and the lexical or word-like elements of language as the atoms (minimal units) of computation [2009: 199]. This is pretty close to Simon's combinatoric play and building blocks - but even so, computers may be evolving in novel directions. Near the end of Turing's Cathedral, George Dyson speculates about the future of calculating, with an oddly different approach that exceeds units and addresses to describe something more in keeping with visual calculating. For me, this was a pleasant discovery 
Given the access to content-addressable memory, codes based on instructions that say, "Do this with that"-without having to specify a precise locationwill begin to evolve. The instructions may even say, "Do this with something like that" - without the template having to be exact. The first epoch in the digital era began with the introduction of the random-access storage matrix in 1951. The second era began with the introduction of the Internet. With the introduction of template-based addressing, the third era in computation has begun. What was once a cause for failure-not specifying a precise numerical address_-will become a prerequisite to real-world success [2012: 309].

Whether this is an accurate prediction for computers or not, isn't a concern. Rather, it points to what shape grammars do, and relates them to computers. In fact, it's one of the few places I've found in computer science where there's something that resonates closely with shape grammars-von Neumann is already conspicuous, and then there's Newton's method for polynomials, as an advance on Turing machines, and the footing for numerical analysis and scientific calculating. Lenore Blum, Felipe Cucker, Michael Shub, and Steve Smale do the math; they begin with von Neumann's talk at the Hixon Symposium in 1948, in which he contrasts the continuous methods of analysis with the discrete methods of logic, noting the ease of the former and the combinatorial rigors of the latter [1951: 16]. (Von Neumann does visual analogies here, too [1951: 23-24]). Blum and partners add to this-they

believe that the Turing machine as a foundation for real number algorithms can only obscure concepts [1998: 23].

Moreover, they argue that

A Turing machine for implementing Newton's method, by reducing all operations to bit operations, would wipe out its basic underlying mathematical structure [1998: 38].

It's like this for visual calculating-with shape grammars for real number algorithms or Newton's method, and insight for concepts. The key difference in shape grammars is embedding, and this easy extension of identity clouds the definition of shape grammars in Turing machines. And note that visual calculating and Newtonian calculating align in some basic ways. Turing machines are a special case for both, and there are algebras (infinite rings), etc. Art and science are equally telling in calculating. Taking the time to think about painting, and art and design, reveals as much about calculating as thinking about science and numerical analysis - and might show more with its focus on seeing. A return to real numbers isn't the sole way to extend calculating. To slight painting, and art and design, and stress science and engineering only, even as fruitful as they are for airplanes, bridges, computers, etc. in an ABC of STEM, diminishes calculating. Is it any wonder that artists and designers shun calculating-it's too spare for art and design — or that scientists and engineers find it easy to ignore other modes of reverie and mood? It seems that everyone is ready to crimp experience for the ease of familiar things. This is neither shape grammars nor Wilde. There's full-bodied calculating in both. 
Shape grammars make Dyson's "template-based addressing" possible with as much formal, mathematical rigor as anyone might ever demand, in terms of embedding, assignments, and transformations-just as they manage object-oriented programming and Wittgenstein's polygons. Embedding brooks failure and even encourages it; it's all about content (shapes and their parts) and ignores precise numerical addresses (they're dispersed and depend on how rules are tried). Content and addresses meld as one, and aren't usefully distinguished. Then, assignments and transformations make a convincing start on what it means for shapes and things to be alike-in a personal way depending on the artist/critic. Dyson's third era in computation may actually date to 40 years ago, when I first showed how embedding and transformations make shape grammars work [1975]. Is a "shape-machine" a physical possibility? Is real-world success with computers now in sight? I'm not sure, but it's something to think about, especially if what computers do is supposed to accord with art and design, and maybe even science. Otherwise, what I can see and what computers can do will invariably conflict, highlighting the inescapable drawbacks of computers today. What do limits like this accomplish? Shape grammars are too useful to be held back in this way, for what they show about calculating and for what they do in art and design. I like to think that visual calculating is the real success, on computers or not.

Wilde's critic as artist approaches art as if there's nothing to it

All art is quite useless [1982: 236].

The only beautiful things ... are the things that do not concern us. As long as a thing is useful or necessary to us ... or is a vital part of the environment in which we live, it is outside the proper sphere of art [1982: 299].

When a thing is useful and a vital part of life, it has a definite description, namely, its use, that's hard, if not impossible, to ignore-Marcel Duchamp pulls this off with readymades. The "use" of a useful thing lowers the likelihood for other descriptions. I have no choice, but to see it as in itself it really is. There isn't any room for art- to say what as in itself it really is not. Wilde is very canny about this, when he uses his critical method reflexively. He's a creative artist- "I live in terror of not being misunderstood. Don't degrade me into the position of giving you useful information" [1982: 349]. Wilde wants to be misunderstood because the alternative-conveying definite facts and figures, or always being sincere-isn't art. (Language seems trivially for communication-it's a knack I have to change the subject to suit myself). This is another reason for Simon and Sutherland to prefer computers to draftsmen-they give us useless drawings instead of useful information. All shapes are quite useless, when I calculate in shape grammars. This is the nub of visual calculating. Otherwise, mere combinatoric play with building blocks exceeds what I need-with the terrifying prospect of always being useful (described or measured in merely one way) in a utilitarian paradise. This is no fancy. Computers as in themselves they really are, are why utility works [Streitfeld 2015]. (Wilde espouses Socialism, and not because it's utilitarian. For Wilde, "Socialism itself will be of value simply because it will lead to Individualism" [1982: 257]. That's an odd coincidence. Simon finds painting in social planning, as 
Wilde locates the critic as artist in Socialism. To no one's surprise, art and politics align without rhyme or reason. The art of politics is to see the world as in itself it really is and struggle to change it-to remake the world as in itself it really is not. But no change is ever the last. There's no doing it right, without it all being strangely different later on. That's why visual analogies matter to von Neumannthey're variable and incomplete, and later on, they're not the way they were. Try as he will, he can't shake the vague and queasy feeling that nothing is fixed and final. There's no end to painting, and to politics as usual. The trick is going on-Epicurus encourages seeing and plurality, and Wilde adds in modes of reverie and mood, as shape grammars calculate with embedding and rules).

Of course, there are other ways to think about this-the claim that art is useless isn't new with Wilde. John Ruskin finds uselessness essential in architecture- "a vital part of the environment in which we live"-if it's to surpass mere building to become an art of its own. He adds art to building in this way

Let us, therefore, at once confine the name to that art which, taking up and admitting, as conditions of its working, the necessities and common uses of the building, impresses on its form certain characters venerable or beautiful, but otherwise unnecessary. Thus, I suppose, no one would call the laws architectural which determine the height of a breastwork or the position of a bastion. But if to the stone facing of that bastion be added an unnecessary feature, as a cable moulding, that is Architecture. It would be similarly unreasonable to call battlements or machicolations architectural features, so long as they consist only of an advanced gallery supported on projecting masses, with open intervals beneath for offence. But if these projecting masses be carved beneath into rounded courses, which are useless, and if the headings of the intervals be arched and trefoiled, which is useless, that is Architecture. ... Architecture concerns itself only with those characters of an edifice which are above and beyond its common use [1981: 16].

The ready embellishment of a building with decoration and ornament impressed on its form is architecture. I guess this is Wilde's aesthetic method, literally. And figuratively - try to frame a firmer metaphor than "art is architecture". No one doubts that decoration and ornament are useless. In Wilde's terms, I have no pressing reason to describe them in either this way or that, so I'm totally free to describe them entirely for myself - after all, decoration and ornament are beautiful forms. In fact, Wilde praises decorative art as an impulse and source for purely creative and critical work. His appeal for a forceful kind of aesthetic formalism neatly anticipates the original spirit of shape grammars and their use in art and design - the focus of the first paper on shape grammars was on painting and sculpture, and how to describe these visual modes in a generative scheme [Stiny and Gips 1972]. Unaware of it at the time, this was congruent, perhaps necessarily, with Alberti's way of describing architecture that separates form and material [1999: 7]. (It's worth noting, too, that my generative scheme lets me switch freely between form and material, to develop them reciprocally). But Wilde is best as himself, and fervent about decorative art 
By its deliberate rejection of Nature as the ideal of beauty, as well as of the imitative method of the ordinary painter, decorative art not merely prepares the soul for the reception of true imaginative work, but develops in it that sense of form which is the basis of creative no less than of critical achievement. For the real artist is he who proceeds, not from feeling to form, but from form to thought and passion [1982: 398].

When I started out with shape grammars, I instinctively emphasized strict abstraction and hard-edged geometric form, because this let me see-without being distracted by the common meanings of familiar and useful things. My effort to see went always "from form to thought and passion". My eyes were aglitter, calculating with shapes that were forever alive with varying possibilities-surprises that my rules let me see. I regret now that I didn't read Wilde then. But I was probably too self-absorbed seeing to pay very much attention to a writer. Who would imagine that his odd company could add to an exciting personal adventure to create something more enjoyable than it already was? I suppose that any prolegomena to shape grammars is possible only afterward-when ambiguity and misdirection are a delight without any irritable search for source and influence. The new seeks mooring, not to drift away. Shapes are like this when I calculate with rules, and it's the reason for everything I say, and, undoubtedly, repeat more than once. Repetition has its own aesthetic form, and at every pulse, there's the opportunity to see things differently. (The weavers of Ancient Greece banned the everyday use of the checkerboard pattern - the paradigm of visual repetition-precisely because it was too unstable. And of course, this goes for the line, as well). The central materials I use to teach are much the same every year, especially in my graduate seminar, but entirely new each time. So I try them again, and wait and see. Shape grammars let in insight.

But Wilde's absolute kind of uselessness may ask too much. Isn't it enough that decoration and ornament don't add anything to what I'm trying to do now, even if they're useful in other irrelevant ways? I can discard them without loss to my immediate goal of building - they're beyond the necessities of common use. All I need is this relative kind of uselessness for art in architecture and possibly, in added disciplines, as well. In fact, there may be art in calculating if there are useless rules-whatever kind of uselessness this is. But it's vital that calculating be a science, so innovation can join it when it's no longer an art but a science, too. Some easy ways to keep calculating a science, and to keep art out, are well known. These show once more how visual calculating with shape grammars readily exceeds what symbolic calculating with Turing machines is expected to do. What's useful when I calculate depends on shapes and symbols being the same. Of course, this is Turing's combinatory sense of symbols rather than Wilde's evocative sense. Wilde handles symbols "not as expressive but as impressive purely" - they are as in themselves they really are not. Wilde puts this in a striking formula- "All art is at once surface and symbol" [1982: 236]. This goes for shapes, as well. Shapes are all surface and entirely superficial. They're merely what's apparent now, with no structure of any kind that's deep, hidden, or underlying. That's why shapes vary with the rules I try-there's nothing to keep them fixed. In essence, what you see is what you get. 
And in symbols, there are untold things- "Beauty has as many meanings as a man has moods. Beauty is the symbol of symbols" [1982: 368]. Shapes are surface and symbol in any way I wish. Turing's symbols are all units, invariant 0's and 1's. I know-that's their power and beauty.

Useless rules have fascinated me for years [1996]. The most conspicuous ones are in the schema $\mathrm{x} \rightarrow \mathrm{x}$, for example, this rule

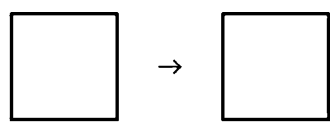

that says a square is a square. (To be precise, the shape in the left-hand side of a rule is "this," and in the right-hand side, "that". Names are too definite, and restrict what I see). The rules in $\mathrm{x} \rightarrow \mathrm{x}$ are identities. But it doesn't mean much that this is this. That seems useless enough-it's an empty tautology-however, there's more uselessness to come. Identities don't change anything when I use them to calculate. If I try my rule for squares on the large, outside square and on the small, inside square in the shape

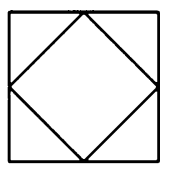

I can calculate trivially so

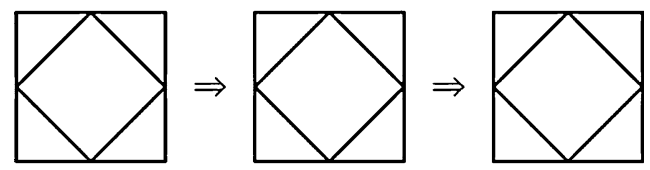

simply doing nothing. And if I go on to try the identity rule for triangles

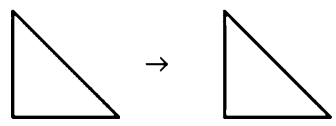

clockwise from the bottom-left triangle, or in whatever order you want, I get the longer, but still redundant series

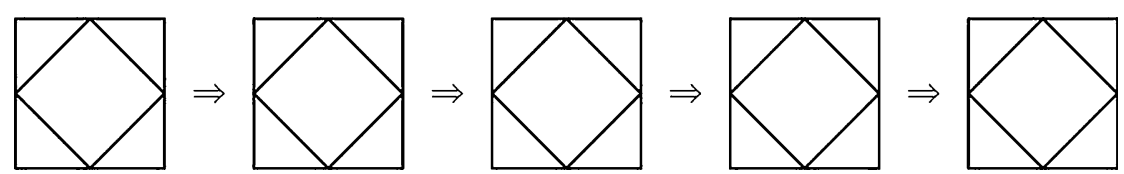

Identity rules can be eliminated without loss - and coders, especially graduate students, rush to do this. Although Ruskin might demur, it's somehow very satisfying to get rid of useless things you don't need-it's a modernist obsessionbut is it the proper thing to do in shape grammars? Calculating in this way doesn't 
go anywhere. Nothing changes either for squares or triangles-but that's not really what happens. A shape is seamless and undivided before I try a rule. Identities let me pick out the parts I see as I calculate, and define trees that show alternative ways of doing this. The shape

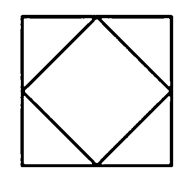

is first two squares, one inscribed in the other

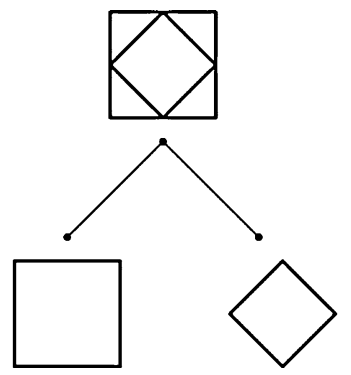

and then four triangles arranged around a tacit square

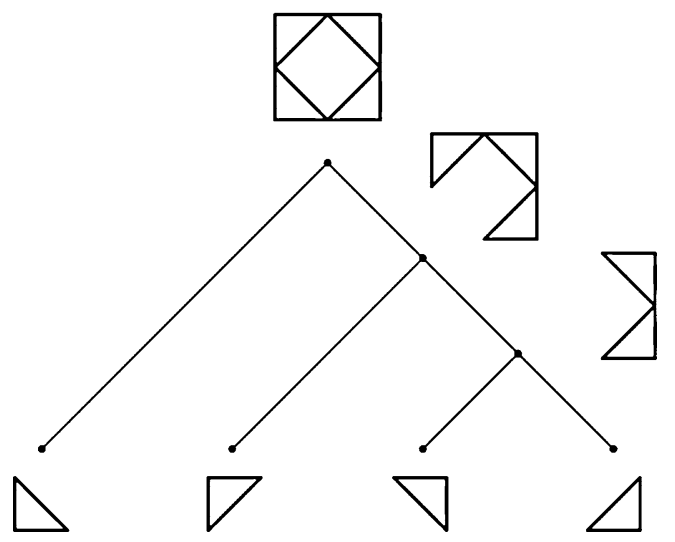

Both trees are instances of the scheme 


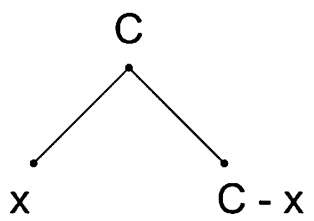

for hierarchies, that's defined for identity rules in $\mathrm{x} \rightarrow \mathrm{x}$. The scheme is recursive- $\mathrm{I}$ can use it again for $\mathrm{x}$ or for its relative complement $\mathrm{C}-\mathrm{x}$. And the scheme is easy to extend in terms of the schema $\mathrm{x} \rightarrow \operatorname{prt}(\mathrm{x})$ for parts, so that it's

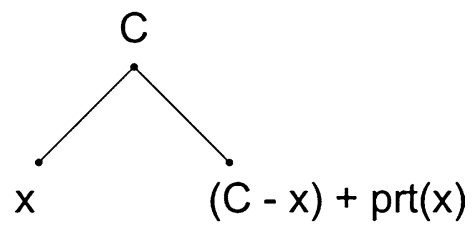

Now the two trees above are each defined by use of erasing rules in the schema $\mathrm{x} \rightarrow$ that complements $\mathrm{x} \rightarrow \mathrm{x}$. Both erasing and identity are properly included in $\mathrm{x} \rightarrow \operatorname{prt}(\mathrm{x})$. For squares, the erasing rule is

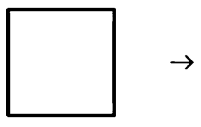

and for my triangles, it's

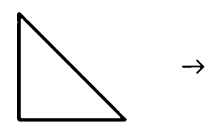

What kind of tree is defined if I use identity rules in $\mathrm{x} \rightarrow \mathrm{x}$ ? And what happens if $\mathrm{I}$ use rules in $\mathrm{x} \rightarrow \operatorname{prt}(\mathrm{x})$ that are neither identity rules nor erasing rules? There are plenty of ways I can describe shapes when I try different rules. (A given vocabulary may limit the rules I try. Designers, especially architects, are invariably looking for one to inform their work. But this rarely makes sense without calculating first).

Additionally, my two trees combine in a more elaborate graph or network 


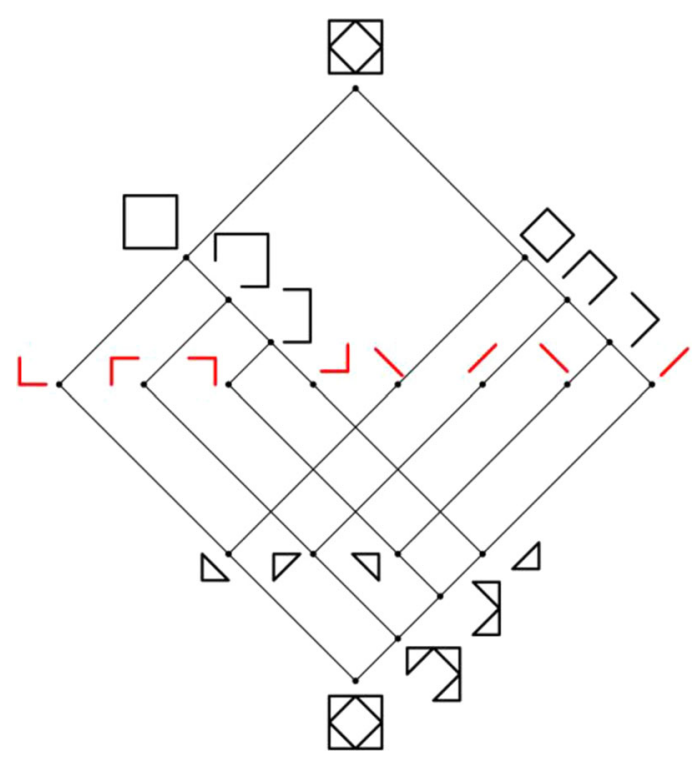

to describe what I see, switching back and forth between squares and triangles. At the top, the shape

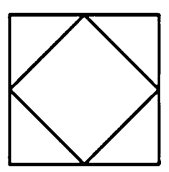

is described as two squares, what as in itself it really is, and at the bottom, it's described as four triangles, what as in itself it really is not. But the red elements in the middle show how this pair of contradictory descriptions can merge, so that squares and triangles as in themselves they really are not. As a result, I can see the shape in alternative ways. And I can complicate the graph-endlessly-if I try other identity rules in the schema $\mathrm{x} \rightarrow \mathrm{x}$ (or erasing rules in the schema $\mathrm{x} \rightarrow$ ), maybe identities for pentagons and hexagons like the ones here
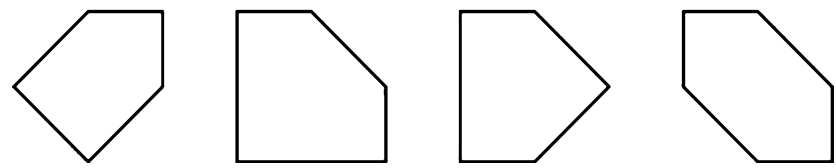

But perhaps this is too predictable-big K's and little k's vary in size in any way I please, and for k's, also in shape. Identity rules are useless because they don't change shapes when I use them to calculate, but they make up for this because they change what I see. Useless rules have uses-critical ones. Evidently, this goes in some sense for shapes and symbols alike, as I've already suggested for identities such as NP $\rightarrow$ NP that divide sentences into phrases and words. But sentences and other things made with symbols come with invariant divisions in place-fixing parts 
is just grouping symbols. Shapes, in contrast, are utterly undivided. Of course, identities aren't the only kind of useless rules. There are useless rules that separate shapes and symbols more emphatically, and that show how they differ. In the right circumstances, all rules are useless in this way.

In computer science (the theory of formal languages and automata), any rule in a formal grammar (Turing machine) is useless when it contains a non-generating symbol or an unreachable one [Hopcroft et al. 2001: 256-259]. Unreachable symbols provide another way to show how rules work in shape grammars. In outline, the core idea is this - a symbol is reachable when it's in the initial string of a grammar or recursively, in the right-hand side of a rule that has only reachable symbols in its left-hand side. This doesn't seem very hard-maybe my initial string is $\mathrm{SSS}$, and my rules are these five: $\mathrm{S} \rightarrow \mathrm{AB}, \mathrm{C} \rightarrow \mathrm{BD}, \mathrm{AD} \rightarrow \mathrm{ABC}, \mathrm{A} \rightarrow \mathrm{a}$, $\mathrm{B} \rightarrow$ b. Starting with $\mathrm{S}$, then recursively S, A, B, and concluding, S, A, B, a, b are the reachable symbols. So, $\mathrm{C}$ and $\mathrm{D}$ are unreachable, and $\mathrm{C} \rightarrow \mathrm{BD}$ and $\mathrm{AD} \rightarrow \mathrm{ABC}$ are useless rules that I'm free to delete. The grammar works fine without them. This is unremarkable for unreachable symbols - there's no way to apply the rules in which they occur. But is this the case if symbols are shapes? Can I tell when shapes are unreachable or not? Let's see how it goes if I try to discard useless rules in shape grammars. With shapes, there are bound to be some surprises.

Suppose I start with the initial shape
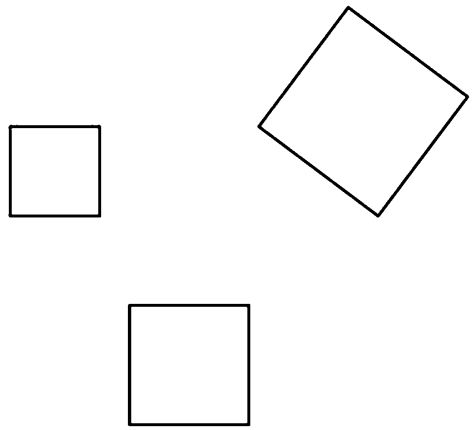

and then calculate as usual in shape grammars with the rule

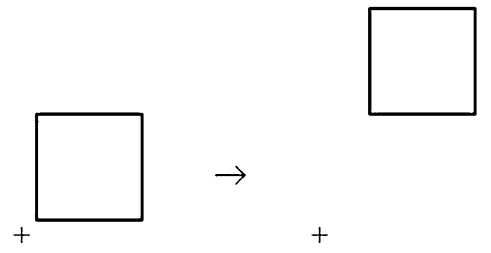

in the transformation schema $\mathrm{x} \rightarrow \mathrm{t}(\mathrm{x})$, that translates a square back and forth 


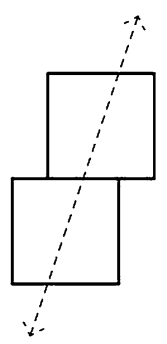

And suppose, too, that I absentmindedly add the rule

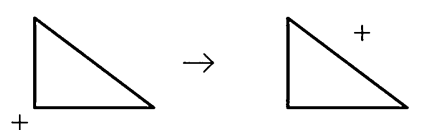

in $\mathrm{x} \rightarrow \mathrm{t}(\mathrm{x})$, and also from this schema, the inverse

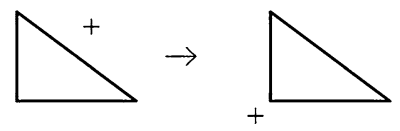

to translate a triangle back and forth, as well

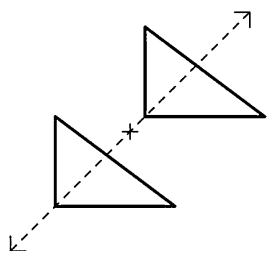

The triangle in the left-hand sides of these rules is neither in the initial shapeobviously there are three squares, if I apply the erasing rule for squares to eliminate them one at a time (this is the proper way to count things, isn't it?) — nor at any place I' $m$ able to see in the right-hand side of the rule that moves a square. Triangles aren't squares-it's pretty clear, the triangle is definitely unreachable, and the rules

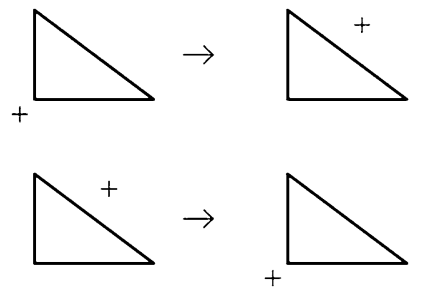

are undeniably useless. My mistake. (The corresponding identity rule is twice useless - first, it's an identity, and then, the triangle is unreachable). But let's see if it's prudent to say this. If I try the rule 


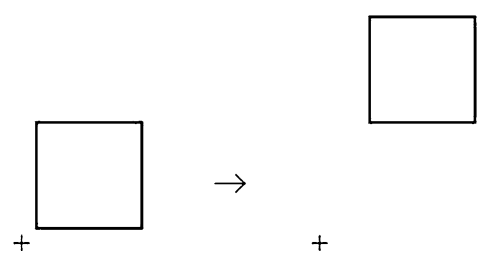

on the largest square and on the smallest square in the shape

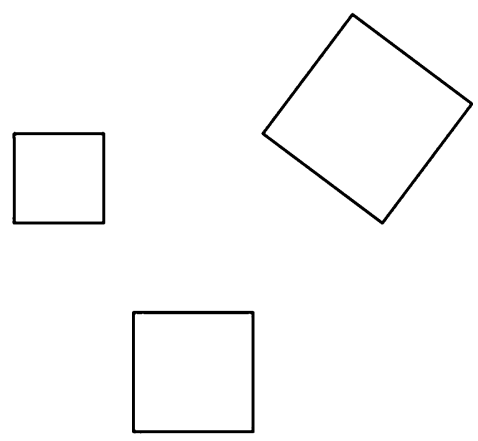

in that order, I get this series of shapes
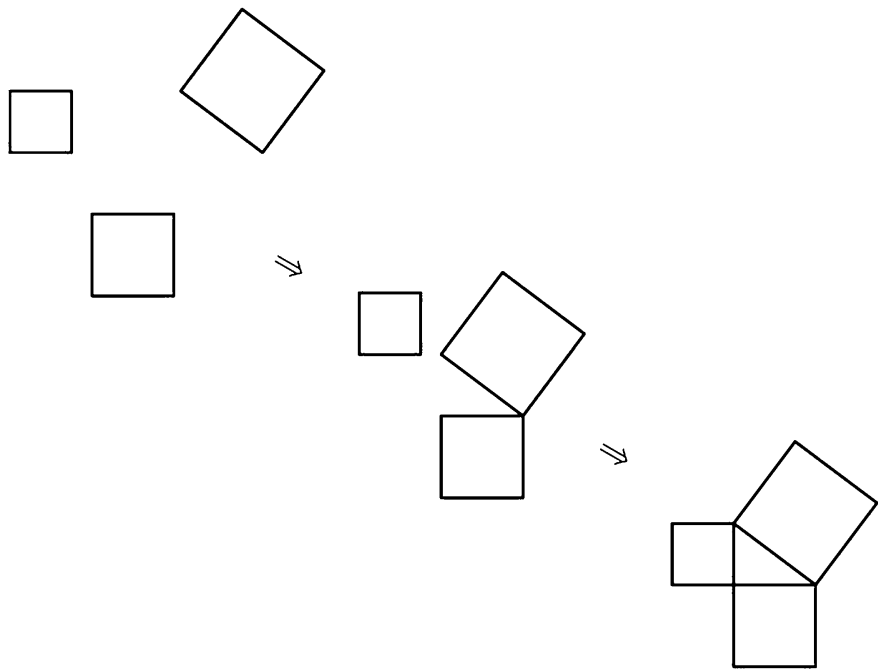

that ends with a Pythagorean figure - that unmistakable symbol of number, rationality, and usefulness. What would students learn in grade school and beyond, especially in STEM subjects, if there were no Pythagorean theorem? But also, it's good for art, as Lionel March shows powerfully in A Book of Kells [2012]. The 
Pythagorean theorem is about right triangles and their sides. It's the formula everyone knows by heart and can recite effortlessly. It's easy to say in words

$$
\mathrm{a}^{2}+\mathrm{b}^{2}=\mathrm{c}^{2}
$$

But this is merely letters and numbers- $-3^{2}+4^{2}=5^{2}$. What made the triangle appear as if by magic, when I started out with three squares, as counting confirms? I can apply the rule

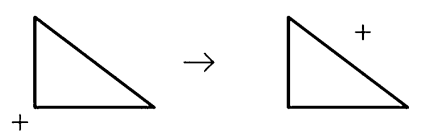

to translate the triangle and thereby calculate some more to get

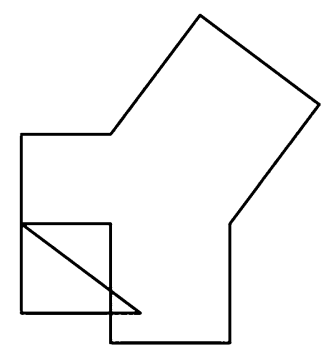

and this hardly seems useless. In fact, it might be very useful. And I can go on in this manner to move the triangle again

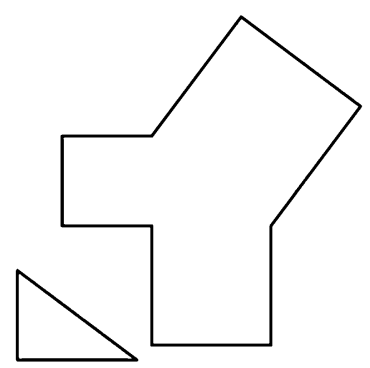

That's kind of strange—who would ever have imagined such a thing? Now my first rule for squares 


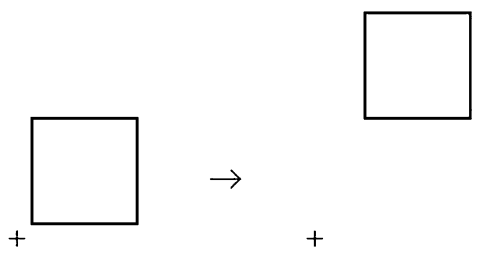

the one that was so useful before, is useless. I suppose this can happen with symbols, too, but then it must be forever. I can use the inverse

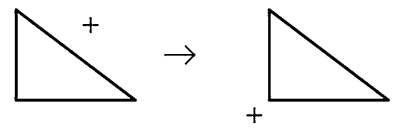

twice to retrieve three squares that pop out all at once, and then move them separately in multiple ways (eight ways for each to be exact, corresponding to the symmetry of the square). I guess useless/useful rules can turn into useful/useless ones, and then switch back again-and, surely, in endless ways. (This is a marvelous source of plots that are worthy of Wilde). A trio of useless rules-two with an unreachable triangle and one with an unreachable square-that I assumed I could discard with nary a qualm, are perfectly useful in obvious ways but at different times. I must be missing something vital-visual calculating and symbolic calculating can't be so distant. Calculating is calculating, isn't it? This seems reasonable-everyone takes it for granted-but it's probably a mistake, even for simple things. It's more likely just the opposite.

But maybe this is simply a misunderstanding. Maybe squares and triangles are really four lines and three lines, respectively, as I was told in school. Why not use these visual analogies (spatial relations)? There must be a good reason for them, although my teachers were totally baffled when I asked for one-why bother about this? And I guess my teachers knew best. It seems lines can be like symbols (0dimensional elements) in visual analogies for squares and triangles, and work just like units as I calculate, so that visual calculating is the same as symbolic calculating. Being practical—taking things as in themselves they really are-works wonders. (This lets me approach my Pythagorean figure as Wittgenstein does a Necker cube using constituents related in alternative ways, and skirt what he does adding polygons, in reverie it would seem in terms of embedding. This highlights the key difference between set grammars for spatial relations and shape grammars [Stiny 1982]. I tried the latter, but failed to distinguish useful and useless rules).

The initial shape, exploded a little bit to separate "symbols", is 12 lines 


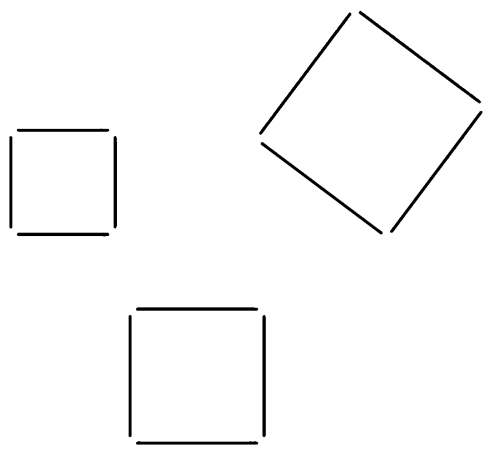

that are all units, and my three rules, also in exploded versions, are
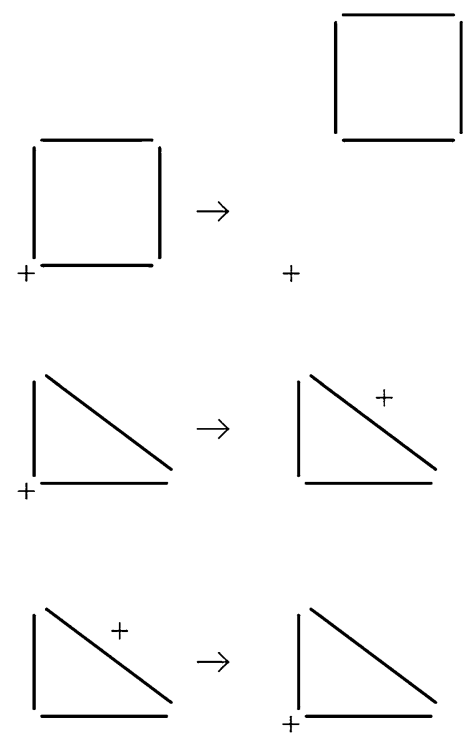

Lines are reachable-they're in my initial shape and the only symbols in my rules - and so, no rule is useless, even if it's hard to imagine how rules for triangles might be used. That's the reason to calculate-to find out-and when I do, everything works 

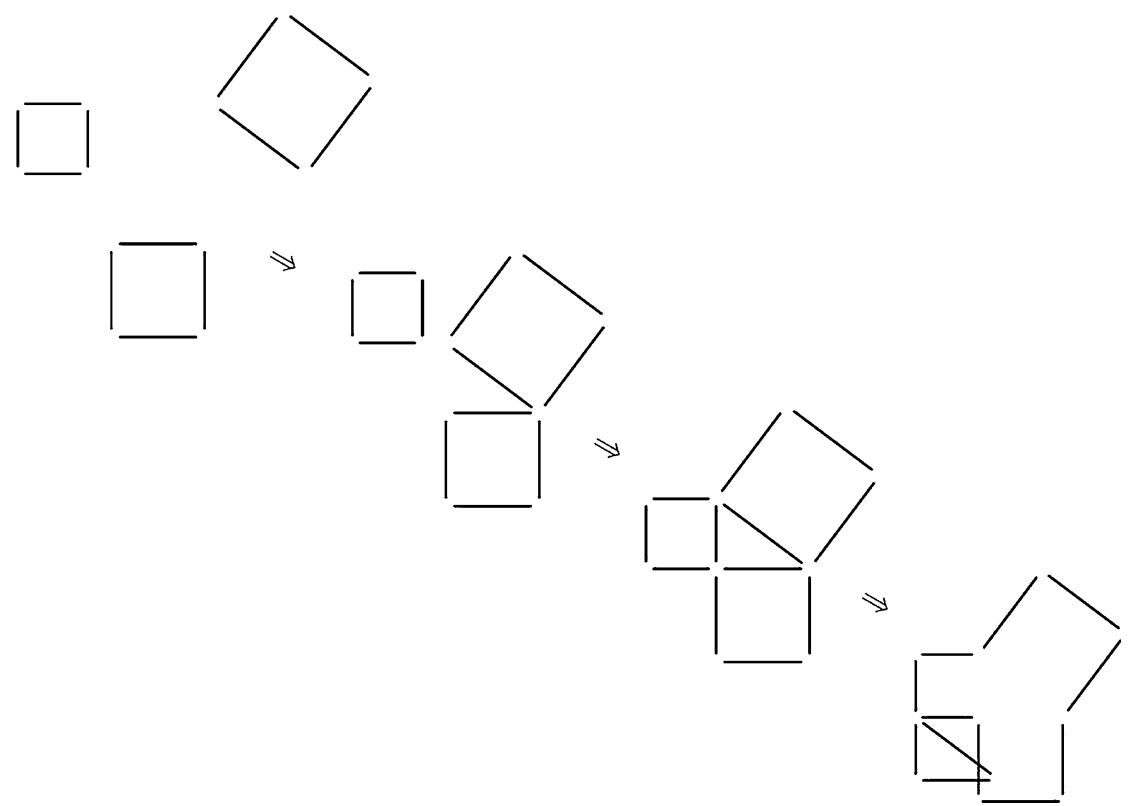

"Education is an admirable thing"-if I keep strictly to the lines in squares and triangles. But are these visual analogies really a sure thing? Do I need to add any more details to be positive that they're complete? And how and when do I know this? Consider the little triangles in red-the so-called "emergent" ones

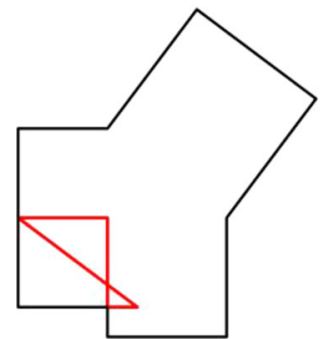

I should be able to move them, as well-with embedding I can, if triangles are undivided and not lines that are symbols in a visual analogy. And what about the emergent square in red

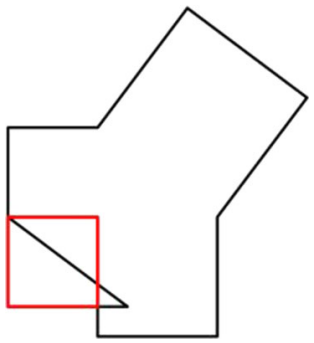


In fact with these surprises, my three rules should all be useful. But I can't move either of the triangles or the square because they don't have sides-lines (symbols) put in by my rules - or they have fewer sides than they need. And suppose they did have sides, then what would happen to the lines in my three initial squares and in the triangle they contain? How many additional rules are necessary to make any of this work? All of a sudden, things seem to be getting awfully complicated-simply trying to move squares and triangles around. Neither individual shapes nor shapes in rules can be described before I calculate. It may be that squares and triangles are actually lines, but how do I know which ones? Can I find out just by looking at my initial shape and my rules? This is OK in formal grammars-symbols are given in advance and are always the same-but it seems useless in shape grammars. I can't decide what I'll see before I've seen it, and I need embedding and rules for this. In shape grammars, I have to calculate to find out if the shape in the left-hand side of a rule is reachable or not-it's never enough to look at the initial shape and the other rules - and this makes it hard, no, it makes it impossible, to tell. There's nothing I can do before I try my rules, to find out what's going to happen next. Visual analogies and other descriptions aren't a reliable way to start. They rarely work and are usually misleading without calculating first. There are untold possibilities that are worth knowing - but for most, this means going on. They can't be taught.

The use of embedding makes a huge difference. Once again, useless rules turn out to be useful. And this may be it for uselessness-it's easy to cook up examples like mine for squares and triangles for any polygons, and in fact, for any shapes made up of linear elements. There are endless things to see, but this, no doubt, is enough for now. It seems visual calculating with shape grammars isn't the same as symbolic calculating with Turing machines. In the latter, symbols are as in themselves they really are-is this the end of Wilde and his wanton aesthetic method, and of painting, and art and design? I suppose calculating isn't seeing, after all-unless calculating as in itself it really is not. That's what I've been trying to show. I said so parenthetically, at the start of this essay, but perhaps there's a more expressive way to put it. Seeing (embedding) is impressive purely-that's clear enough-and there's a corollary, too

Shapes aren't symbols, alone or in combination.

This is key for Wilde's aesthetic method, and the center of painting, and art and design. Shapes are seamless - they're divided again and again on the fly, in another way every time I try a rule to calculate with what I see. It's what makes modes of reverie and mood possible, with countless changes and contradictions. Seeingusing shape grammars-goes on in ever shifting ways, that no one can know in advance. Embedding animates Wilde's artist/critic. This is the importance of calculating without symbols.

(I asked Gips to look at my Pythagorean example for unreachable squares and triangles, and beyond my influence, he described it so

The squares. Just floating [drifting] down into the Pythagorean figure. And then those two triangles. The first time you see it, it's a total surprise. Once 
you've seen it and look again, there is an inevitability, a destiny to it. A Greek tragedy for calculating with symbols. The inevitable outcome of its tragic flaws [2015].

The Greek spirit is the source of Wilde's artist/critic, whose descriptions are always true. I like this one because it contrasts shapes and symbols as the former leads to surprises that the latter can't handle, and surely within Wilde's critical compass, reverie and mood go anywhere embedding desires. Unexpected or not, tragedy is inescapable as long as symbols describe shapes fully and once and for all in terms of what's already known. No matter the effort put into this, shapes exceed anything that's fixed in advance. Shapes are ineffably sublime).

Whenever I talk about shape grammars, someone invariably feels compelled to explain to all and sundry everything that I've misunderstood-as I ought to. Sometimes this is with a lesson to learn about how things really are, and sometimes, it's with sincere regret, as if I'm lost desperately in a personal (psychotic) reverie. Aficionados of the arts sigh and wring their hands- - he just doesn't get it. Scientists and engineers aren't much better, and may be worse-who told you, you could calculate like that? Ah, the strange conventions of science, but I prefer to see for myself. No matter who stands up, they're keen to recite the same old, useful information, propaganda that's become hard fact. It seems little more than blind prejudice

Art is breaking the rules!

The mere utterance of this formula makes me cringe, and it must-again, I haven't been misunderstood. But somehow it ensures that art and calculating are irredeemably apart. It seems art breaks the rules, so it can't be calculating, because it only follows the rules. Maybe so for symbolic calculating, but this isn't so for visual calculating, where breaking a rule simply means trying another one, or using familiar rules in new ways. That's why Wilde's aesthetic method provides a valuable introduction to shape grammars. Wilde's critic as artist sees the object as in itself it really is not-with rules, I'm free to see in this way, as well, exactly as I please. I can draw two squares and then see four triangles, or pentagons, hexagons, and K's and k's, etc. There's simply no end to breaking the rules. Ambiguity and like uncertainties - change, contradiction, incompleteness, inconsistency, etc.- - are the nub. Some of my protagonists promote this, some don't. But getting them to agree isn't the problem-the trick is to exploit ambiguity, as I calculate. This requires embedding, so that any rule I try works. Whether I'm consistent or not doesn't make any difference-I can go on. Nothing blocks my way. It's worth repeating - rules apply with no inherent memory, so I'm seeing for the first time, every time I look. And what I see-anything at all—corresponds to a rule. There's no way around this, because what I see is a shape. Of course, the insistent question remains of whether I can predict the rule I'll try next or not. In answering this, I invariably opt for not-picking a rule to use is exactly the same as putting an interpretation into a Rorschach test. Ballard's goal of using brain computation to explain Michelangelo and Shakespeare isn't as crazy as it sounds. Each of us 
calculates in a unique way, as "a function of [our] whole personality and [our] whole previous history". Brain computation may do the job, but not without Michelangelo and Shakespeare as artists who can't be described, and critics to see their pictures and plays, etc. Artist-computers aren't enough. This may be reassuring, but it's irrelevant. The rule I try, whatever it is, works now, no matter what I see without ever having to re-describe this in another way tailored to the rule. How do I do that? Rules forget what I've seen and neglect my plans; they needn't respect the past to work, or anticipate what's to come. Embedding lets me drift freely in an open-ended process, to play myself fully. It's the way Wilde's critic works - as an artist.

In an earlier essay, I asked the question

What rule(s) should I use?"

and gave the seemingly cavalier response

Use any rule(s) you want, whenever you want to [2011: 15].

But this is a far from trivial answer-in visual calculating with shape grammars, I can try any rule I want, to get a result. This is evident for useless rules-especially, for identity rules in the schema $\mathrm{x} \rightarrow \mathrm{x}$, that let me see freely in any way. And my schemas provide heuristics to define an unlimited repertoire of rules that add to Wilde's modes of reverie and mood, and to Alberti's landscapes dense with the contours and outlines of real and fancied things. This can't help but include the novel and unexpected. I drift with every passion, to see as I please. In fact, I've already given three primary schemas that are a productive place to start. These are the part schema $x \rightarrow \operatorname{prt}(x)$, the transformation schema $x \rightarrow t(x)$, and the boundary schema $x \rightarrow b(x)$ [2011: 17]. From these, I can define more in six ways, in terms of subsets, copies, inverses, adding, composition, and Boolean combination-there are, no doubt, other ways, as well. For example, my primary schemas yield the coloring book schema

$$
\mathrm{x} \rightarrow \mathrm{x}+\mathrm{b}^{-1}(\mathrm{x})
$$

when I add the subset $x \rightarrow x$ of $x \rightarrow \operatorname{prt}(x)$ or $x \rightarrow t(x)$ to the inverse of $x \rightarrow b(x)$. For a building plan in lines, this does poché for walls or fills in rooms, depending on the shape I assign to the variable x. Going from one to the other is something like an epiphany or Gestalt switch. There are rules for anything I wish, for insight and delight-surprises abound. (In reverie, I sometimes match up the heuristic force of schemas and embedding with that of Harold Bloom's six "revisionary ratios" [1997: 14-16]. I try other matchups, too, but in this one, revision-seeing again-is key, and then acting on what I see, even doing nothing. Bloom meets the extravagant eye with description, and "When [one] describes [one] is a poet" [Wilde 1982: 361] — "the turbulence of the sublime needs representation lest it overwhelm us" [Bloom 2011: 21]. Greek weavers tried to ban instability early on, and my rules offer temporary refuge in trees and graphs, in topologies, and in other kinds of ad 
hoc structure. But this isn't what rules are for; they let me go on, in ways that alter everything I see. The sublime won't be calmed).

My schemas and rules are also an effective way to teach art and design that values Wilde's outlook on education, and they include use. Shape grammars assume Wilde's aesthetic method without loss to the other two-thirds of the Vitruvian canon. Separately, Firmness and Commodity are equal to Delight. This has been a durable standard in architecture, and it's not too bad for art and design, with varying weight on each of its three categories - after all, art is architecture. But typically, computers exhaust Firmness and Commodity; they handle the necessities of common use, with scant attention to Delight. Still, there are alternative standards-I can try the thoroughly modernist formula

$$
\text { Firmness }+ \text { Commodity }=\text { Delight }
$$

Not surprisingly, early applications of computers in architecture-no, applications even today-invoke this formula confidently. And there's immense truth in ituseful things can work in very beautiful ways, as in themselves they really are. At heart, I'm actually an engineer. But shape grammars include Delight in Wilde's aesthetic (critical) sense. That's the really hard problem to crack by calculating, but it seems it's bad manners to try. That's the reason I focus on it a lot, to the exclusion of Firmness and Commodity. This is wrong, and I know it. It's lucky for me that there's an easy fix already in place-remember that symbolic calculating with Turing machines (computers) is a special case of visual calculating with shape grammars. As a result, both Firmness and Commodity are categories I know how to use, at least to the extent that anyone else does. It's high time to pay attention to this, and to apply shape grammars in art and design to embrace the entire Vitruvian canon with its three coequal categories in this expression

$$
\text { Firmness }+ \text { Commodity }+ \text { Delight }
$$

There's a lot to calculate in each category alone, or as they go together in diverse ways. Sundry visual techniques and symbolic ones have been tried for all of this that allow for the categories to interact reciprocally in n-ary relations to define designsand many of these devices for shape grammars have been around for a longtime. There's an excess of useful promise. I can use shape grammars to see the object as in itself it really is not, as I pay equal attention to its use. And Wilde may not be very far behind - at least this possibility is worth considering anon

Ernest. Ah! You admit, then, that the critic may occasionally be allowed to see the object as in itself it really is.

Gilbert. I am not quite sure. Perhaps I may admit it after supper. There is a subtle influence in supper [1982: 371]. 


\section{References}

Alberti, Leon Battista. 1972. On Painting and Sculpture. The Latin Texts of De Pictura and De Statua. Cecil Grayson, ed. and trans. London: Phaidon.

Alberti, Leon Battista. 1999. On the Art of Building in Ten Books. J. Rykwert, N. Leach, R. Tavernor, trans. Cambridge, MA: The MIT Press.

Ballard Dana. 2015. Brain Computation as Hierarchical Abstraction. Cambridge, MA: The MIT Press. Blake, William. 1974. To George Cumberland 12 April 1827. P. 878 in Blake: Complete Writings. G. Keynes, ed. London: Oxford University Press.

Bloom, Harold. 1997. The Anxiety of Influence: A Theory of Poetry. New York: Oxford University Press.

Bloom, Harold. 2011. The Anatomy of Influence: Literature as a Way of Life. New Haven, CT: Yale University Press.

Blum, Lenore, Felipe Cucker, Michael Shub and Steve Smale. 1998. Complexity and Real Computation. New York: Springer-Verlag.

Chomsky, Noam. 2009. The Mysteries of Nature: How Deeply Hidden? The Journal of Philosophy CVI, 4: 167-200.

Chomsky, Noam. 2014, March 3. Chomsky Lecture Series. Department of Linguistics and Philosophy, MIT.

Diogenes Laertius. 1950. Lives of the Eminent Philosophers, Volume II: Books 6-10. R. D. Hicks, trans. Loeb Classical Library 185. Cambridge, MA: Harvard University Press.

Dyson, George. 2012. Turing's Cathedral: The Origins of the Digital Universe. New York: Pantheon Books.

Eisner, Elliot W. 2002. The Arts and the Creation of Mind. New Haven, CT: Yale University Press.

Gips, James. 2015, July 18. A Greek Tragedy. Personal e-mail.

Gondek, David. 2014, February 19. Conversations on Art and Science: Tricksters of Big Data-Artificial Intelligence or Intelligent Artifice. School of the Art Institute of Chicago. David Gondek on Vimeo: www.vimeo.com.

Healy, Chris. 1904. Confessions of a Journalist, 2nd ed. London: Chatto \& Windus.

Hopcroft, John E., Rajeev Motwani and Jeffery D. Ullman. 2001. Introduction to Automata Theory, Languages, and Computation, 2nd ed. Boston: Addison Wesley.

Keats, John. 1958. The Letters of John Keats: 1814-182, Volume One. Hyder Edward Rollins, ed. Cambridge, MA: Harvard University Press.

Kohler, Wolfgang. 1951. Cybernetics of Control and Information in the Animal and the Machine (Review of Book). Social Research 18, 1: 125-130.

Lawrence, D. H. 1993. Poetry of the Present. Pp. 181-186 in The Complete Poems. Vivian De Sola Pinto and F. Warren Roberts, eds. New York: Penguin Books.

March, Lionel. 2012. The Book of Kells. https://www.flickr.com/photos/lionelmarch/sets/

McCarthy, John. 2009. Reminiscence: Why SAIL and Not Something Else, the History of A. I. http:// saildart.org/jmc2012.html.

McCulloch, Warren S. 1965. What is a Number that a Man May Know It, and a Man, that He May Know Number? Pp. 1-18 in Embodiments of Mind. Cambridge, MA: The MIT Press.

Ruskin, John. 1981. The Seven Lamps of Architecture. New York: Farrar, Straus, and Giroux.

Shakespeare, William. 2009. A Midsummer Night's Dream. Barbara A. Mowat and Paul Werstine, eds. Folger Shakespeare Library. New York: Simon \& Schuster.

Simon, Herbert A. 1981. The Sciences of the Artificial, 2nd ed. Cambridge, MA: The MIT Press.

Smith, Brian Cantwell. 1996. On the Origin of Objects. Cambridge, MA: The MIT Press.

Stiny, George. 1975. Pictorial and Formal Aspects of Shape and Shape Grammars. Basel: Birkhäuser.

Stiny, George. 1982. Spatial Relations and Grammars. Environment and Planning B 9: 113-114.

Stiny, George. 1996. Useless Rules. Environment and Planning B: Planning and Design 23: $235-237$.

Stiny, George. 2006. Shape: Talking about Seeing and Doing. Cambridge, MA: The MIT Press. www. stinyshape.org.

Stiny, George. 2011. What Rule(s) Should I Use? Nexus Network Journal 13, 1: 15-47.

Stiny, George and James Gips. 1972. Shape Grammars and the Generative Specification of Painting and Sculpture. Pp. 1460-1465 in Information Processing 71. C. V. Freiman, ed. Amsterdam: NorthHolland. 
Stiny, George and James Gips. 1978. Algorithmic Aesthetics: Computer Models for Criticism and Design in the Arts. Berkeley and Los Angeles: University of California Press. www.algorithmicaesthetics. org.

Streitfeld, David, 2015, August 17. Data Crunching Is Coming to Help Your Boss Manage Your Time. The New York Times. www.nytimes.com.

Sutherland, Ivan. 1975. Structure in Drawings and the Hidden-Surface Problem. Pp. 73-77 in Reflections on Computer Aids to Design and Architecture, N. Negroponte, ed. New York: Petrocelli/Charter.

Von Neumann, John. 1951. The General and Logical Theory of Automata. Pp. 1-31 in Cerebral Mechanisms in Behavior: the Hixon Symposium. Lloyd A. Jeffress, ed. New York: John Wiley.

Von Neumann, John. 1966. Theory and Organization of Complicated Automata. pp. 29-87 in Theory of Self-reproducing Automata. Arthur W. Burks, ed. Urbana, IL: University of Illinois Press.

Wilde, Oscar. 1982. The Artist as Critic: the Critical Writings of Oscar Wilde. Richard Ellmann, ed. Chicago: University of Chicago Press.

Wittgenstein, Ludwig. 1967. Remarks on the Foundations of Mathematics. Cambridge, MA: The MIT Press.

Wittgenstein, Ludwig. 1977. Tractatus Logico-Philosophicus. London: Routledge \& Kegan Paul.

George Stiny is Professor of Design and Computation at the Massachusetts Institute of Technology in Cambridge, Massachusetts. He joined the Department of Architecture in 1995 after 16 years on the faculty of the University of California, Los Angeles, and currently heads the PhD program in Design and Computation at MIT. Educated at MIT and at UCLA, where he received a PhD in Engineering, Stiny has also taught at the University of Sydney, the Royal College of Art (London), and the Open University. His work on shape and shape grammars is widely known for both its theoretical insights linking seeing and calculating, and its striking applications in design practice, education, and scholarship. Stiny's third book is Shape: Talking about Seeing and Doing (The MIT Press, 2006); he is the author of Pictorial and Formal Aspects of Shape and Shape Grammars (Birkhäuser, 1975), and (with James Gips) of Algorithmic Aesthetics: Computer Models for Criticism and Design in the Arts (University of California Press, 1978). 